\title{
Transdermal buprenorphine and fentanyl patches in cancer pain: a network systematic review
}

Jin Seok Ahn',Johnson Lin', Setsuro Ogawa $^{3}$, Chen Yuan ${ }^{4}$, Tony O'Brien ${ }^{5,6}$, Brian $\mathrm{HC} \mathrm{Le}^{7}$, Andrea M Bothwell ${ }^{8}$, Hanlim Moon', Yacine Hadjiat', Abhijith Ganapathi ${ }^{9}$

'Division of Hematology and Oncology, Samsung Medical Center, Sungkyunkwan University, Seoul, South Korea; ${ }^{2}$ Division of Hematology and Oncology, Department of Internal Medicine, Mackay Memorial Hospital, Taipei, Taiwan, Republic of China; ${ }^{3}$ Department of Anesthesiology, Nihon University School of Medicine, Tokyo, Japan; ${ }^{4}$ Department of Oncology, Tongji Hospital,

Tongji Medical College of Huazhong University of Science and Technology, Wuhan, People's Republic of China; ${ }^{5}$ Marymount University Hospital and Hospice, ${ }^{6}$ Cork University Hospital, College of Medicine and Health, University College Cork, Cork, Ireland; ' ${ }^{7}$ Department of Palliative Care, Royal Melbourne Hospital, Parkville, VIC Australia; ${ }^{8}$ n Vivo Communications (Asia), ${ }^{9}$ Mundipharma Pte Ltd, Singapore, Singapore

\section{Video abstract}

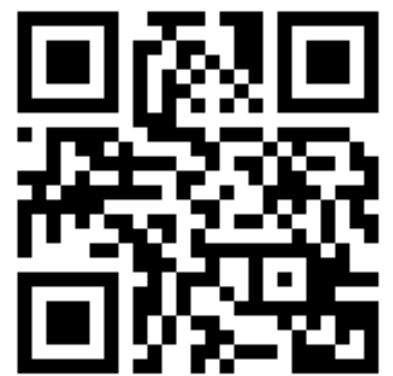

Point your SmartPhone at the code above. If you have a QR code reader the video abstract will appear. Or use: http://youtu.be/L_hle_ydw60

Correspondence: Tony O'Brien Department of Palliative Medicine, Marymount University Hospital \& Hospice, Curraheen,

Cork, Ireland TI2A7I0.

Tel +353 2l 450 I20 I

Email tony.obrienI@hse.ie
This article was published in the following Dove Press journal: Journal of Pain Research

18 August 2017

Number of times this article has been viewed

Abstract: Treatment of cancer pain is generally based on the three-step World Health Organization (WHO) pain relief ladder, which utilizes a sequential approach with drugs of increasing potency. Goals of pain management include optimization of analgesia, optimization of activities of daily living, minimization of adverse effects, and avoidance of aberrant drug taking. In addition, it is recommended that analgesic regimens are individualized and simplified to help ensure patient compliance and should provide the least invasive, easiest, and safest route of opioid administration to ensure adequate analgesia. Buprenorphine and fentanyl are two opioids available for the relief of moderate-to-severe cancer pain. Available clinical data regarding the transdermal (TD) formulations of these opioids and the extent to which they fulfill the recommendations mentioned earlier are systematically reviewed, with the aim of providing additional information for oncologists and pain specialists regarding their comparative use. Due to lack of studies directly comparing TD buprenorphine with TD fentanyl, data comparing these with other step-3 opioids are also evaluated in a network fashion.

Keywords: analgesia, cancer pain management, chronic pain/drug therapy, drug evaluation, pain management, patch analgesics

\section{Plain language summary}

This review provides additional information for oncologists and pain specialists regarding the comparative efficacy and safety of buprenorphine and fentanyl 3-4-day patches in cancer pain management, especially in areas such as Asia where clinical experience with transdermal (TD) buprenorphine is low. Data regarding the buprenorphine 3-4-day patch and the fentanyl 3-day patch were systematically reviewed. Due to lack of studies directly comparing buprenorphine and fentanyl, data comparing these with other step-3 opioids (e.g., oral morphine, oxycodone, and methadone) were also examined. TD buprenorphine and TD fentanyl appear to have similar efficacy and tolerability. The buprenorphine 3-4-day patch may have a reduced risk of tolerance compared with the fentanyl 3-day patch and appears to be a useful option for patients with renal impairment, because it does not require any dose adjustment. In conclusion, the buprenorphine 3-4-day patch is safe and effective in patients with cancer pain. Due to its extended-release formulation, it is best used in patients with stable and predictable opioid requirements.

\section{Introduction}

Pain is one of the most common symptoms among cancer patients, ${ }^{1}$ estimated to be experienced by $59 \%$ of patients undergoing treatment and more prevalent among patients with advanced disease. ${ }^{2-4}$ Cancer pain is most often caused by the cancer 
itself, but it may also be caused by the treatments received. ${ }^{2,4}$ Prevalence of pain can also depend on the type of cancer, its stage, and patients' tolerance for pain. ${ }^{2,4,5}$ To maximize patient outcomes, pain management with regular pain assessment is an essential part of oncologic management. ${ }^{1}$ There is evidence that cancer survival is linked to symptom control, and that pain management contributes to improved quality of life (QoL). ${ }^{6}$

Treatment of cancer pain is generally based on the World Health Organization (WHO) pain relief ladder, ${ }^{3,7}$ which proposes a three-step sequential approach corresponding to drugs with increasing efficacy. ${ }^{8}$ However, more recently published guidelines by the European Association for Palliative Care (EAPC) and the European Society for Medical Oncology (ESMO) suggest giving low doses of strong opioids as an alternative to weak opioids to achieve better analgesia and tolerability. ${ }^{7,9}$ Since the introduction of the three-step WHO ladder in 1986, the use of opioids has increased, although there are geographical variations in use. ${ }^{10}$ Goals of pain management include ${ }^{1,11}$ optimization of analgesia, optimization of activities of daily living, minimization of adverse effects (AEs), and avoidance of aberrant drug taking. For ongoing care, guidelines recommend oral or transdermal (TD) medications including extended-release or long-acting agents with rescue doses, and analgesic regimens are simplified for improved patient compliance. ${ }^{1}$ The least invasive, easiest, and safest route of opioid administration should be provided to ensure adequate analgesia. ${ }^{1,3}$ It is worth noting that when the WHO first published its Cancer Pain Relief Guidelines in 1986, there were no TD formulations available; thus, the intention was to shift the analgesic route of administration from parenteral to oral.

Adverse events are common with opioids, ${ }^{1,7}$ and include constipation, nausea and vomiting, pruritus, delirium, respiratory depression, motor and cognitive impairment, and sedation. ${ }^{7,12}$ Preemptive management of opioid-induced AEs, such as constipation, is important for patient compliance and QoL, ${ }^{13,14}$ thus ensuring effective pain treatment. ${ }^{1,15}$ Patients should be regularly reassessed and pain regimens modified to meet patient-specific goals for comfort, function, and safety. ${ }^{1,7}$ Opioid switching should be considered if pain is inadequately controlled despite adequate dose titration, or in the presence of persistent AEs. ${ }^{1,9}$ No single opioid is optimal for all patients. ${ }^{1}$ In the presence of significant opioid-related AEs, switching to an equivalent dose of an alternative opioid may help improve the balance between analgesic efficacy and AEs. ${ }^{16,17}$
Buprenorphine and fentanyl are two strong opioids available for the relief of cancer pain. Buprenorphine is a semi-synthetic partial $\mu$-opioid receptor agonist as well as a $\kappa$ - and $\delta$-opioid receptor antagonist. It binds to receptors with high affinity and has slow dissociation, contributing to a relatively long duration of analgesic action. ${ }^{11,18-21}$ Fentanyl is a synthetic, highly lipid-soluble, $\mu$-opioid receptor agonist with a low molecular weight. ${ }^{11,18,22,23}$ In contrast to buprenorphine, fentanyl has fast receptor association/dissociation kinetics. ${ }^{20}$ Buprenorphine is available as parenteral, sublingual, and TD formulations, whereas fentanyl can be administered by the parenteral, spinal, TD, transmucosal, buccal, and intranasal routes. ${ }^{22,23}$ With regard to the TD formulations, TD buprenorphine preparations vary across countries, with either 3-4- or 7-day dosing schedules, depending on preparation availability, while fentanyl has a 3-day dosing schedule.

TD opioid delivery avoids first-pass metabolism by the liver, increasing bioavailability and limiting variation in plasma concentration. ${ }^{11,24}$ Increased drug bioavailability enables the use of lower drug doses, thus reducing the incidence of AEs. ${ }^{11}$ TD delivery of opioids also allows consistent, long-term pain relief with continuous controlled release of opioid for 72-168 hours; ${ }^{24}$ as such, they are best reserved for opioid-tolerant patients with stable opioid requirements. ${ }^{7,25}$ Buprenorphine and fentanyl are particularly suited for TD administration since they combine the necessary characteristics (low molecular mass, high lipid solubility, and high potency) for good penetration of the skin. ${ }^{11,18,19,23}$ While oral opioids are generally the first choice, ${ }^{1,26}$ TD medications are recommended by guidelines for ongoing care of patients with cancer pain ${ }^{1}$ and are preferred by many patients because they are noninvasive, easy to use, and their interference with daily activities is minimal. ${ }^{18,24,27}$ TD buprenorphine and TD fentanyl are usually the treatment of choice for patients who are unable to swallow, patients with poor tolerance to morphine, and patients with poor compliance. 1,7,9,11,18,26,27

The aim of this review was to provide additional data for oncologists and pain specialists regarding the use of TD buprenorphine and TD fentanyl in cancer pain management, particularly in areas such as Asia where clinical experience with the use of TD buprenorphine is low. ${ }^{28}$ This review systematically examines the available data for the buprenorphine 3-4-day patch and the fentanyl 3-day patch. Due to lack of studies directly comparing TD buprenorphine and TD fentanyl, data comparing these with other step-3 opioids are also evaluated in a network fashion. 


\section{Methods}

\section{Search strategy}

PubMed, EMBASE, and Cochrane library databases were used for the literature search, which was conducted on March 6,2017 . The search was performed using the following search string, searching all possible fields and MESH/Emtree terms, where available: (transdermal buprenorphine AND cancer pain) OR (transdermal fentanyl AND cancer pain) OR (transdermal buprenorphine AND transdermal fentanyl) OR (transdermal buprenorphine AND transdermal fentanyl AND cancer pain). The search was limited to studies in human beings and NOT "non-cancer pain." Ad hoc searching was also performed, and the reference lists of all included articles were hand searched to identify additional articles.

\section{Study selection}

Eligibility was initially assessed using titles and abstracts. Those that were not excluded were further screened using full-text articles. Articles included in the analysis were studies related to the use of TD buprenorphine and TD fentanyl for the relief of cancer pain and were either direct comparisons or indirect comparisons with other pain medications. Articles excluded from the analysis were study protocol/design, letters, commentaries/news, case reports, studies in non-cancer pain, patient surveys, studies with irrelevant treatments, and narrative reviews. Resulting studies were filtered to select only those studies that examined the use of TD buprenorphine and/or TD fentanyl patches in cancer pain.

\section{Data extraction and assessment of study quality}

Data collected from the articles included study design, patients, treatment characteristics, and results/endpoints. Outcomes examined included analgesic efficacy (pain scores, pain intensity difference [PID], proportion of responders), safety, switching outcomes (dosing, rescue medication), QoL, patient satisfaction/patient preference, and costs.

\section{Results}

\section{Included studies}

A PRISMA flow diagram showing the screening process and reasons for exclusion is shown in Figure 1. A total of 109 studies were identified from searching PubMed, EMBASE, and Cochrane library databases, one additional study was identified from hand searching the reference lists of identified articles, ${ }^{29}$ and one study was identified by ad hoc searching. ${ }^{30}$ The major reason for discarding articles was that they were non-comparative studies, or that they were general reviews or non-English language articles. In total, six studies that compared TD buprenorphine and TD fentanyl and 11 studies that compared TD buprenorphine and/or TD fentanyl with other pain medications were identified. Among studies

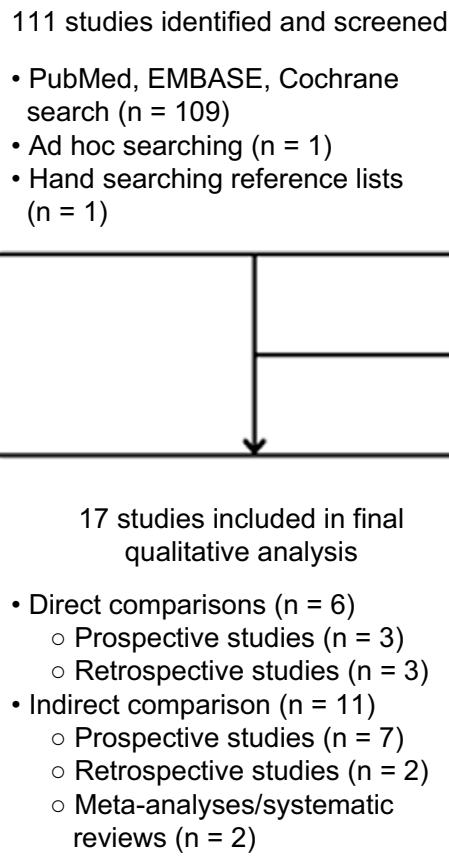

\section{Reasons for exclusion}

- Non-comparative study $(n=24)$

- General review $(n=22)$

- Non-English paper $(n=15)$

- Irrelevant comparison $(n=10)$

- Non-cancer pain $(n=11)$

- Case reports/series $(n=4)$

- Other formulations $(n=3)$

- Irrelevent drug $(n=2)$

- Guidelines ( $n=1)$

- Irrelevant outcomes $(n=1)$

- Pediatric study $(n=1)$

Figure I PRISMA flow diagram of the study selection process. 
comparing TD buprenorphine and TD fentanyl, three were prospective, ${ }^{24,31,32}$ of which one was a direct comparison of TD buprenorphine and TD fentanyl, ${ }^{31}$ and three studies were retrospective. ${ }^{33-35}$ Among studies comparing TD buprenorphine and/or TD fentanyl with other pain medications, the majority (seven studies) were prospective, ${ }^{29,36-41}$ two were retrospective, ${ }^{42,43}$ and two were meta-analyses or systematic reviews. ${ }^{30,44}$ Table 1 presents the design of included studies comparing TD buprenorphine with TD fentanyl, and Table 2 presents the design of included studies comparing TD buprenorphine and/or TD fentanyl with other pain medications.

\section{Utilization of TD buprenorphine and TD fentanyl}

Two studies reported outcomes associated with utilization of TB buprenorphine or TD fentanyl in patients with cancer pain. ${ }^{33,37}$ Of these one study directly compared TD buprenorphine with TD fentanyl ${ }^{33}$ and one study compared TD buprenorphine and/or TD fentanyl with other pain medications. ${ }^{37}$

\section{Direct comparisons}

A retrospective study examined mean prescribed doses of TD buprenorphine and TD fentanyl to compare calculated equipotent oral morphine doses. ${ }^{33}$ Of 2544 patients in a German database who had received $\geq 1$ prescription for TD buprenorphine or TD fentanyl for cancer pain, mean prescribed daily doses were lower with TD buprenorphine than with TD fentanyl. ${ }^{33}$ Equipotent oral daily morphine doses, calculated using current conversion ratios, were statistically significantly lower with TD buprenorphine than with TD fentanyl $(P<0.001){ }^{33}$

\section{Indirect comparisons}

Preliminary analysis of 330 patients enrolled in a multicenter, observational study in Italy showed that $56.7 \%$ of patients received a strong opioid. ${ }^{37}$ Fentanyl and buprenorphine TD delivery systems were the most regularly prescribed $(23.8 \%$ and $9.6 \%$ of patients, respectively). Morphine and oxycodone were prescribed in $11.3 \%$ and $10.8 \%$ of patients, respectively, while methadone was prescribed in only $1 \% .{ }^{37}$

\section{Analgesic efficacy of TD buprenorphine and TD fentanyl}

Eight prospective studies ${ }^{29,31,36-41}$ and three retrospective studies $^{34,35,42}$ reported results regarding the efficacy of TD buprenorphine and TD fentanyl. Of these, three studies directly compared TD buprenorphine with TD fentanyl ${ }^{31,34,35}$ and eight studies compared TD buprenorphine and/or TD fentanyl with other pain medications. ${ }^{29,36-42}$

The majority of studies evaluating the efficacy of TD buprenorphine and TD fentanyl were short-term studies ( $\leq 3$ months) except for two retrospective studies, which evaluated patterns of dosage changes for almost 1 year. ${ }^{34,35}$

\section{Direct comparisons}

A prospective study comparing TD buprenorphine and TD fentanyl revealed that TD buprenorphine in patients with

Table I Studies comparing TD buprenorphine with TD fentanyl

\begin{tabular}{|c|c|c|c|c|c|}
\hline Reference & Study design & $\mathbf{n}$ & Patient characteristics & Treatment & Outcomes \\
\hline \multicolumn{6}{|l|}{ Prospective } \\
\hline Aurilio et $\mathrm{al}^{24}$ & Prospective & 32 & $\begin{array}{l}\text { Chronic cancer pain; } \\
\text { insufficient analgesia }\end{array}$ & $\begin{array}{l}\text { TD buprenorphine, TD } \\
\text { fentanyl }\end{array}$ & $\begin{array}{l}\text { Dosing } \\
\text { Analgesic efficacy } \\
\text { AEs } \\
\text { Rescue medication }\end{array}$ \\
\hline Melilli et $\mathrm{a}^{31}$ & $\begin{array}{l}\text { Observational, parallel- } \\
\text { group, active-control }\end{array}$ & 42 & $\begin{array}{l}\text { Outpatients with cancer; } \\
\text { impaired renal function }\end{array}$ & $\begin{array}{l}\text { TD buprenorphine vs TD } \\
\text { fentanyl }\end{array}$ & $\begin{array}{l}\text { Analgesic efficacy } \\
\text { AEs } \\
\text { Rescue medication }\end{array}$ \\
\hline Mercadante et $\mathrm{al}^{32}$ & $\begin{array}{l}\text { Within-patient, two-way } \\
\text { crossover }\end{array}$ & 22 & $\begin{array}{l}\text { Optimally managed for } \\
\text { cancer pain }\end{array}$ & $\begin{array}{l}\text { TD buprenorphine } \rightarrow \text { TD } \\
\text { fentanyl vs TD fentanyl } \\
\rightarrow \text { TD buprenorphine }\end{array}$ & $\begin{array}{l}\text { Analgesic efficacy } \\
\text { AEs } \\
\text { Rescue medication }\end{array}$ \\
\hline \multicolumn{6}{|l|}{ Retrospective } \\
\hline Sittl et $\mathrm{al}^{33}$ & & 2544 & $\begin{array}{l}\text { Received } \geq \mid \text { prescription for } \\
\text { cancer pain }\end{array}$ & $\begin{array}{l}\text { TD buprenorphine, TD } \\
\text { fentanyl }\end{array}$ & Dosing \\
\hline Sittl et $\mathrm{al}^{34}$ & Longitudinal & 446 & Cancer pain & $\begin{array}{l}\text { TD buprenorphine, TD } \\
\text { fentanyl }\end{array}$ & $\begin{array}{l}\text { Dosing } \\
\text { Rescue medication }\end{array}$ \\
\hline Sittl et $\mathrm{al}^{35}$ & & 605 & Cancer pain & $\begin{array}{l}\text { TD buprenorphine, TD } \\
\text { fentanyl }\end{array}$ & Dosing \\
\hline
\end{tabular}

Abbreviations: AEs, adverse effects; TD, transdermal. 
Table 2 Studies comparing TD buprenorphine and/or TD fentanyl with other pain medications

\begin{tabular}{|c|c|c|c|c|c|}
\hline Reference & Study design & $\mathbf{n}$ & Patient characteristics & Treatment & Outcomes \\
\hline \multicolumn{6}{|l|}{ Prospective } \\
\hline Ahmedzai et $\mathrm{al}^{36}$ & $\begin{array}{l}\text { Multicentre, } \\
\text { randomized }\end{array}$ & 202 & $\begin{array}{l}\text { Palliative care, receiving } \\
\text { stable doses of morphine }\end{array}$ & TD fentanyl vs morphine & $\begin{array}{l}\text { Analgesic efficacy } \\
\text { AEs } \\
\text { QoL } \\
\text { Patient preference }\end{array}$ \\
\hline van Seventer et $\mathrm{a}^{29}$ & $\begin{array}{l}\text { Multicentre, } \\
\text { randomized, open- } \\
\text { label }\end{array}$ & $|3|$ & $\begin{array}{l}\text { Moderate-to-severe cancer } \\
\text { pain }\end{array}$ & TD fentanyl vs oral morphine & $\begin{array}{l}\text { Analgesic efficacy } \\
\text { AEs } \\
\text { QoL }\end{array}$ \\
\hline Apolone et $\mathrm{a}^{37}$ & $\begin{array}{l}\text { Multicentre, open- } \\
\text { label, observational }\end{array}$ & 330 & Cancer & $\begin{array}{l}\text { TD buprenorphine, TD fentanyl, } \\
\text { morphine, oxycodone, methadone }\end{array}$ & $\begin{array}{l}\text { Drug utilization } \\
\text { Analgesic efficacy }\end{array}$ \\
\hline Kress et a ${ }^{38}$ & $\begin{array}{l}\text { Multicentre, } \\
\text { randomized, open- } \\
\text { label, parallel }\end{array}$ & 220 & $\begin{array}{l}\text { Requiring WHO/step-3 } \\
\text { opioids }\end{array}$ & $\begin{array}{l}\text { TD fentanyl (Matrifen } ® \text { 3-day } \\
\text { patch) vs standard opioid treatment } \\
\text { (TD fentanyl [Durogesic } ® \text { patch] or } \\
\text { oral opioids) }\end{array}$ & $\begin{array}{l}\text { Analgesic efficacy } \\
\text { AEs }\end{array}$ \\
\hline Mercadante et al ${ }^{39}$ & $\begin{array}{l}\text { Multicentre, } \\
\text { randomized }\end{array}$ & 108 & $\begin{array}{l}\text { Advanced cancer; pain } \\
\text { requiring strong opioids; } \\
\text { previously received opioids } \\
\text { for mild-to-moderate pain }\end{array}$ & $\begin{array}{l}\text { TD fentanyl vs oral morphine or } \\
\text { methadone }\end{array}$ & $\begin{array}{l}\text { Analgesic efficacy } \\
\text { AEs } \\
\text { QoL } \\
\text { Costs }\end{array}$ \\
\hline Payne et $\mathrm{a}^{41}$ & $\begin{array}{l}\text { Multicentre, cross- } \\
\text { sectional }\end{array}$ & 504 & Advanced cancer & TD fentanyl vs oral morphine & $\begin{array}{l}\text { Analgesic efficacy } \\
\text { AEs } \\
\text { QoL } \\
\text { Patient satisfaction }\end{array}$ \\
\hline Wong et $\mathrm{a}^{40}$ & Open, randomized & 40 & Terminal cancer pain & TD fentanyl vs oral morphine & $\begin{array}{l}\text { Analgesic efficacy } \\
\text { AEs } \\
\text { Patient satisfaction }\end{array}$ \\
\hline \multicolumn{6}{|l|}{ Retrospective } \\
\hline Corli et al $\mathrm{a}^{42}$ & $\begin{array}{l}\text { Exploratory analysis } \\
\text { of a prospective, } \\
\text { observational study }\end{array}$ & 258 & WHO/step-3 opioid naive & $\begin{array}{l}\text { TD buprenorphine, TD fentanyl, } \\
\text { morphine, oxycodone }\end{array}$ & $\begin{array}{l}\text { Analgesic efficacy } \\
\text { AEs } \\
\text { Rescue medication }\end{array}$ \\
\hline Mercadante et $\mathrm{al}^{43}$ & Multicentre & 201 & $\begin{array}{l}\text { Palliative care in a home } \\
\text { setting }\end{array}$ & $\begin{array}{l}\text { TD buprenorphine, TD } \\
\text { fentanyl, morphine, oxycodone, } \\
\text { hydromorphone }\end{array}$ & $\begin{array}{l}\text { Analgesic efficacy } \\
\text { AEs } \\
\text { Switch rate } \\
\text { Dosing } \\
\text { Route of } \\
\text { administration }\end{array}$ \\
\hline \multicolumn{6}{|c|}{ Systematic reviews/meta-analyses } \\
\hline Tassinari et $\mathrm{al}^{44}$ & $\begin{array}{l}\text { Meta-analysis } \\
\text { (four studies) }\end{array}$ & 425 & Cancer pain & $\begin{array}{l}\text { TD buprenorphine or TD fentanyl } \\
\text { vs morphine }\end{array}$ & $\begin{array}{l}\text { AEs } \\
\text { Patient preference }\end{array}$ \\
\hline Hadley et $\mathrm{a}^{30}$ & $\begin{array}{l}\text { Meta-analysis (four } \\
\text { studies) }\end{array}$ & 258 & $\begin{array}{l}\text { Outpatients with moderate- } \\
\text { to-severe chronic cancer } \\
\text { pain }\end{array}$ & TD fentanyl vs oral morphine & AEs \\
\hline
\end{tabular}

Abbreviations: AEs, adverse effects; QoL, quality of life; TD, transdermal; WHO, World Health Organization.

renal impairment was as effective at controlling moderateto-severe cancer pain as TD fentanyl in patients without renal impairment. ${ }^{31}$ Median Numerical Rating Scale (NRS) scores were $8.0(95 \%$ CI 7.4, 8.4) at enrollment for both treatment groups. NRS pain score reductions were significant and constant over time, with no significant differences in pain scores between TD buprenorphine and TD fentanyl treatment groups. ${ }^{31}$ The mean dose of TD buprenorphine increased by $48 \%$ and $26 \%$ at days $10-30$ and days 30-90, respectively, whereas corresponding dose increases for TD fentanyl was $34 \%$ and $38 \%$, respectively. ${ }^{31}$ There were no statistically significant differences in the use of rescue medication between the two treatment groups. ${ }^{31}$

Comparison of dosing in a retrospective study of 446 patients with cancer pain from a German database showed that, during treatment, increases in mean prescribed dosages were significantly greater with TD fentanyl than with TD buprenorphine (mean percentile change: $42.7 \%$ vs $21.7 \%$; $P<0.05) .{ }^{34}$ Mean daily increases were $0.11 \%$ and $0.07 \%$ for TD fentanyl and TD buprenorphine, respectively $(P<0.05) .^{34}$ No significant differences between treatment groups were reported for the use of rescue medication. ${ }^{34}$ The authors 
of the study suggested that tolerance development may be higher with TD fentanyl than with TD buprenorphine. ${ }^{34} \mathrm{~A}$ similar German study in 605 patients with cancer pain confirmed these results. ${ }^{35}$ A significantly greater proportion of TD buprenorphine recipients had stable dosages throughout treatment than patients receiving TD fentanyl $(50.0 \%$ vs $26.2 \% ; P<0.05) .{ }^{35}$ Compared with TD buprenorphine, the proportion of patients with alternating dosage changes was significantly greater in patients receiving TD fentanyl $(30.6 \%$ vs $11.8 \% ; P<0.05) .{ }^{35}$ In addition, over the entire treatment duration, mean percentage increases in dosage were significantly higher in the patients receiving TD fentanyl than those receiving TD buprenorphine $(81.4 \%$ vs $34.5 \% ; P<0.05) .{ }^{35}$

\section{Indirect comparisons}

Retrospective exploratory analysis of data from a prospective study demonstrated that reductions in PID were similar between TD buprenorphine and TD fentanyl for average pain $(-2.32$ vs -2.51$)$, but slightly better with TD buprenorphine for worst pain $(-2.94$ vs -2.46$) .{ }^{42}$ Full responders (defined as a PID $\geq 30 \%$ ) appeared to be slightly more frequent with TD buprenorphine than with TD fentanyl for both average pain $(70.7 \%$ vs $68.2 \%)$ and worst pain (62.9\% vs $54.5 \%)$. Switching opioids due to the lack of efficacy or AEs were less frequent with TD buprenorphine than with TD fentanyl $(8.6 \%$ vs $20.0 \%$ ). Recipients of TD fentanyl required greater dose increases than recipients of TD buprenorphine: increases in dose $\geq 5 \%$ a day were observed in $33.3 \%$ of patients receiving TD fentanyl compared with $15.5 \%$ of patients receiving TD buprenorphine $(P<0.05)$.

Analysis of Index of Pain Management in an Italian Outcomes Research study in 330 patients suggested that, despite them receiving strong opioids, patients were undertreated. ${ }^{37}$ While one study reported no significant differences in pain control with TD fentanyl vs oral morphine, significantly more rescue medication was used by patients treated with TD fentanyl (53.9\% vs $41.5 \%$ of treatment days; $P=0.0005) .{ }^{36}$ Similar efficacy has been reported for comparisons of TD fentanyl with standard opioid treatment. ${ }^{29,38}$

No differences in pain intensity or non-opioid analgesic consumption were reported in a prospective, randomized study of TD fentanyl compared with oral morphine or methadone. ${ }^{39}$ These results were confirmed in a study comparing TD fentanyl with oral morphine, with composite pain scores similar between treatment groups, ${ }^{41}$ and in a study of 40 patients switched from immediate-release oral morphine to TD fentanyl or controlled-release oral morphine. ${ }^{40}$

\section{Safety of TD buprenorphine and TD fentanyl}

Seven prospective studies, ${ }^{29,31,36,38-41}$ one retrospective study, ${ }^{42}$ and two meta-analyses ${ }^{30,44}$ reported tolerability data for TD buprenorphine and TD fentanyl. Of these, one study directly compared TD buprenorphine with TD fentany ${ }^{31}$ and nine studies compared TD buprenorphine and/or TD fentanyl with other pain medications. ${ }^{29,30,36,38-42,44}$

\section{Direct comparisons}

A prospective study directly comparing TD buprenorphine with TD fentanyl revealed similar rates of AEs despite patients treated with TD buprenorphine having renal impairment vs no renal impairment in those receiving TD fentanyl. ${ }^{31}$ The most common AEs were somnolence/confusion, nausea/ vomiting, constipation and pruritus. ${ }^{31}$ No patients required dose reduction or treatment interruption. ${ }^{31}$

\section{Indirect comparisons}

Side effects appear to be less bothersome with TD fentanyl than with oral morphine..$^{29,36,41}$ Rates of constipation, in particular, appear to be lower with TD fentanyl than with oral morphine..$^{29,36,40}$ A meta-analysis comparing AEs of TD opioids and slow-release oral morphine reported a significant advantage of TD opioids for constipation (pooled odds ratio [OR] 0.38; $P<0.001$ ); however, no comparison of TD buprenorphine and TD fentanyl was performed. ${ }^{44}$ Similarly, a Cochrane Database review of TD fentanyl demonstrated a reduction in opioidrelated constipation compared with oral sustained-release morphine ( $28 \%$ vs $46 \%$; risk ratio $0.61 ; 95 \%$ CI $0.47,0.78) .{ }^{30}$

An exploratory analysis of data from a prospective observational noninterventional study examined the rate of AEs in 258 patients receiving TD buprenorphine, TD fentanyl, or oral morphine or oxycodone as standard care. ${ }^{42}$ Univariate analysis of safety outcomes showed a greater proportion of TD fentanyl than TD buprenorphine recipients reported at least one AE symptom described as "much/very much" (71.1\% of 32 patients vs $57.8 \%$ of 67 patients). ${ }^{42}$ Overall, there was significant variability between all treatments $(P>0.05){ }^{42}$ Multivariate comparisons demonstrated ORs of 0.48 (95\% CI $0.21,1.13$ ) for TD buprenorphine and 0.79 (95\% CI 0.29 , 2.16) for TD fentanyl compared with morphine. ${ }^{42}$

Finally, within-group analysis of data from a randomized study revealed significant increases in symptom intensity (nausea-vomiting, drowsiness, constipation, and confusion) during treatment with morphine and methadone but not with TD fentanyl. ${ }^{39}$ 


\section{Switching between TD opioids}

One prospective study and two retrospective studies examined switching between TD opioids. ${ }^{24,32,43}$ Of these, two studies directly compared TD buprenorphine with TD fentany $1^{24,32}$ and one study compared TD buprenorphine and/or TD fentanyl with other pain medications..$^{43}$

Switching between opioids resulted in improvements in pain scores, especially in patients whose pain was previously inadequately controlled. ${ }^{24,43}$ In addition, there were generally no statistically significant differences in pain scores between patients who switched from TD fentanyl to TD buprenorphine and those who switched from TD buprenorphine to TD fentanyl. ${ }^{24,32}$ It is of interest that in one study, a $50 \%$ dose reduction was made while switching between TD opioids, ${ }^{24}$ which is greater than commonly used in practice. Retrospective analysis of data among patients switching opioids during home palliative care revealed that the most frequent reason for switching was convenience because they were no longer able to swallow, especially during the last days of life. A large number of patients switched from oral opioids, such as oral morphine and oxycodone to parenteral morphine $(\mathrm{n}=79)$, TD fentanyl $(n=28)$, or TD buprenorphine $(n=2) .{ }^{43}$ The outcome of switching was good or partial in the majority of patients.

Similarly, use of rescue medication was reduced after switching in patients with previously inadequate analgesia, ${ }^{24}$ but there were no differences between patients who switched from TD fentanyl to TD buprenorphine and those who switched from TD buprenorphine to TD fentanyl. ${ }^{24,32}$ Switching between TD opioids also reduced the incidence of AEs, ${ }^{24}$ with no between-group differences in symptom intensity. ${ }^{32}$

\section{QoL}

Four prospective studies reported data regarding patient $\mathrm{QoL}$ with TD buprenorphine and/or TD fentanyl compared with other pain medications..$^{29,36,39,41}$ There were no significant differences in European Organization for Research and Treatment of Cancer (EORTC) QoL scores between TD fentanyl and oral morphine, but when the aggregated scale for emesis was separated into nausea and vomiting, the mean score for nausea was significantly lower for TD fentanyl $(P=0.04) .{ }^{36}$ Another comparison of TD fentanyl and oral morphine revealed significantly better functioning with TD fentanyl assessed using the Functional Assessment of Cancer Therapy-General (FACT-G) scale $(P<0.001),{ }^{41}$ whereas evaluation of QoL using the Spitzer QoL Index showed no significant differences in QoL scores between TD fentanyl, oral morphine, and methadone.$^{39} \mathrm{~A}$ randomized open-label study revealed significantly less patient-reported interruption of daily activities with TD fentanyl than with sustainedrelease oral morphine ( $12 \%$ vs $37 \% ; P=0.012) .{ }^{29}$

\section{Patient satisfaction/patient preference with TD buprenorphine and TD fentanyl}

Three prospective studies ${ }^{36,40,41}$ and one meta-analysis ${ }^{44}$ reported data regarding patient preference with TD buprenorphine and/or TD fentanyl compared with other pain medications. Two studies comparing TD fentanyl with oral morphine revealed that more patients preferred TD fentanyl over oral morphine. ${ }^{36,41}$ Also, 17 of 20 patients switched from immediate-release oral morphine to TD fentanyl, and 19 of 20 patients switched from immediate-release oral morphine to controlled-release morphine, preferred TD fentanyl and controlled-release morphine, respectively, to immediaterelease oral morphine. ${ }^{40}$ Similarly, meta-analysis of data from three studies revealed a significant advantage of TD opiates compared with slow-release morphine $;{ }^{44}$ however, patient preference with TD uprenorphine vs TD fentanyl was not compared.

\section{Costs}

One prospective study reported data regarding treatment costs with TD fentanyl compared with other pain medications. ${ }^{39}$ The costs of pharmacological cancer pain management, including opioids, symptomatic drugs (i.e., those used to control opioidinduced AEs), and non-opioid drugs, were examined. Among 108 patients receiving TD fentanyl, morphine, or methadone, no significant differences were observed in the cost of drugs used to manage opioid-induced adverse events and non-opioid analgesic drugs used, although methadone was significantly cheaper than TD fentanyl or morphine. ${ }^{39}$ However, the authors noted that other relevant costs (i.e., hospital admissions, visits, contacts, transportation, educational materials, and domestic support) were not included in the analysis.

\section{Discussion}

Findings from this network review have shown that TD buprenorphine and TD fentanyl have similar analgesic efficacy, ${ }^{31,42}$ with TD buprenorphine appearing to be an appropriate choice in patients with renal impairment, showing similar analgesic efficacy and rates of AEs to TD fentanyl in patients without renal impairment. ${ }^{31}$ Indeed, dose adjustments for renal dysfunction are not required for TD buprenorphine or TD fentanyl. ${ }^{27}$ Accordingly, ESMO recommends the use of TD buprenorphine and TD fentanyl as the safest opioids of choice in patients with renal impairment. ${ }^{7}$ The study by Melilli et al ${ }^{31}$ confirms the usefulness of TD buprenorphine 
in patients with renal impairment, and other studies help reinforce that, due to its pharmacokinetic profile, TD buprenorphine can be used in all stages of renal impairment without dose adjustment. ${ }^{45,46}$

In addition, results from our systematic review suggest that there is a potentially reduced risk of developing tolerance with TD buprenorphine than with TD fentanyl, as evidenced by a reduced need for dosage increases, ${ }^{34,47}$ and tolerability may be slightly better with TD buprenorphine than with TD fentanyl, although it is important to note that the small patient population size in this study identified in our systematic review is a limitation. ${ }^{42}$ In addition, there appears to be reduced constipation with TD opioids compared with oral morphine..$^{36,40,44}$ However, based on the available data, no meaningful comment can be made regarding the relative costs of TD opioids.

While the use of oral opioids is more common, ${ }^{1}$ and preferentially recommended in some guidelines, ${ }^{26} \mathrm{TD}$ opioids could be considered first-line therapy for selected patients. National Comprehensive Cancer Network guidelines state that they can be used as indicated to maximize patient comfort, ${ }^{1}$ while other guidelines (ESMO, EAPC, and UK National Health System) state that they are the preferred treatment in patients who are unable to swallow. ${ }^{7,926}$ Other patient groups for whom TD opioids may be particularly useful include those unable to tolerate oral medications, those with poor compliance, and those with renal impairment. ${ }^{7,26}$ However, it is important to note that TD opioids should be reserved for those patients whose opioid requirements are stable. ${ }^{7,26}$

With regard to the safety, TD opioids are relatively well tolerated, with reduced AEs vs oral opioids. ${ }^{27}$ The most frequently reported AEs with TD buprenorphine are headache, dizziness, somnolence, constipation, dry mouth, nausea, vomiting, pruritus, erythema, and application site pruritus and reactions. ${ }^{19,48}$ However, it is important to note that regulatory authorities in the USA and Canada have issued warnings regarding TD fentanyl overdoses and deaths. ${ }^{49-51}$ Factors contributing to adverse drug events include: lack of appreciation that fentanyl is a strong opioid analgesic; inappropriate use in patients naive to strong opioids; lack of patient education regarding safe use, storage, and disposal; lack of awareness of the signs of an overdose; lack of awareness that the absorption rate of fentanyl may be increased if the skin under the patch becomes vasodilated, e.g., in febrile patients or by an external heat source; and lack of awareness of drug interactions increasing fentanyl levels. ${ }^{50-52}$ Rates of constipation $(16 \%-22 \%)$, nausea $(2 \%-9 \%)$, and sedation $(2 \%-11 \%)$ have been reported with TD opioids. ${ }^{27}$ In particu- lar, unlike TD fentanyl, TD buprenorphine has a ceiling effect on respiratory depression without an analgesic ceiling effect, which positively impacts its safety and abuse liability. ${ }^{53,54}$

TD buprenorphine also has a low abuse/physical dependency risk. ${ }^{55}$ After long-term treatment with buprenorphine, withdrawal symptoms are usually mild in intensity with a delayed onset of more than 72 hours. They appear to be milder than those associated with morphine and fentanyl. Due to its slow dissociation from the $\mu$-receptor, the risk of drug dependence and analgesic tolerance appears to be lower with buprenorphine than with other $\mu$-opioids..$^{55}$

An obvious limitation of the current review is the lack of studies directly comparing TD buprenorphine and TD fentanyl, or TD opioids with oral opioids. The previously mentioned Cochrane systematic review concluded that, given its widespread use in the palliative care setting, trial evidence for TD fentanyl is limited and of poor quality, with inadequate data for a meta-analysis. ${ }^{30}$ In addition, studies comparing TD buprenorphine and TD fentanyl are of poor quality, being mostly retrospective, with few long-term data. In particular, more studies examining the relative costs of TD opioids would be useful.

\section{Conclusion}

The aim of this review was to provide additional information for oncologists and pain specialists regarding the comparative use of TD buprenorphine and TD fentanyl in cancer pain management. The authors undertook a comprehensive review of the published literature. Data directly comparing these TD opioids were lacking; however, from the available data, it can be concluded that TD opioids are safe and effective in selected patients with cancer pain, especially those with stable and predictable opioid requirements; the TD delivery route will help to reduce tablet burden and may help compliance in selected patients. TD buprenorphine and TD fentanyl appear to have similar efficacy in patients with cancer pain. In addition, similar to TD fentanyl, TD buprenorphine appears to be particularly useful in patients with renal impairment, requiring no dose adjustment regardless of the stages of impairment. While comparative data suggest similar rates of AEs with TD buprenorphine and TD fentanyl, TD buprenorphine may have a reduced risk of tolerance compared with TD fentanyl, and additional studies show that TD buprenorphine has a ceiling effect on respiratory depression without a ceiling effect on analgesia, suggesting better overall tolerability of TD buprenorphine than TD fentanyl. Further studies directly comparing TD buprenorphine with TD fentanyl in cancer pain would be useful; long-term data, in particular, are lacking. 


\section{Acknowledgment}

Financial support for the writing of this review was provided by Mundipharma Pte Ltd.

\section{Disclosure}

Dr Jin Seok Ahn reports personal fees from BMS, Eisai, Janssen, Roche, Menarini, and Boehringer Ingelheim outside the submitted work. Dr Setsuro Ogawa reports personal fees from Mundipharma K.K. outside the submitted work. Dr Tony O'Brien reports personal fees from Archimedes, AstraZeneca, Grunenthal, Janssen-Cilag, Mundipharma, and Teva outside the submitted work. Dr Andrea Bothwell reports personal fees from In Vivo Communications (Asia) Pte Ltd, the medical communications agency commissioned by Mundipharma Pte Ltd for this project, during the conduct of the study; personal fees from various pharmaceutical companies, outside the submitted work. Dr Hanlim Moon reports personal fees from Mundipharma Pte Ltd during the conduct of the study. Dr Yacine Hadjiat reports personal fees from Mundipharma Pte Ltd during the conduct of the study. Dr Abhijith Ganapathi reports personal fees from Mundipharma Pte Ltd during the conduct of the study. Dr Johnson Lin, Dr Chen Yuan, and Dr Brian HC Le report no conflicts of interest in this work.

\section{References}

1. National Comprehensive Cancer Network. NCCN Clinical Practice Guidelines in Oncology: Adult Cancer Pain. Version 2. 2017. Available from: https://www.nccn.org/professionals/physician_gls/pdf/pain.pdf. Accessed June 13, 2017.

2. van den Beuken-van Everdingen $\mathrm{MH}$, de Rijke JM, Kessels AG, Schouten HC, van Kleef M, Patijn J. Prevalence of pain in patients with cancer: a systematic review of the past 40 years. Ann Oncol. 2007;18(9):1437-1449.

3. Pergolizzi JV Jr, Mercadante S, Echaburu AV, et al. The role of transdermal buprenorphine in the treatment of cancer pain: an expert panel consensus. Curr Med Res Opin. 2009;25(6):1517-1528.

4. Higginson IJ, Murtagh F. Cancer pain epidemiology. In: Bruera ED, Portenoy RK, editors. Cancer Pain Assessment and Management Second Edition. New York: Cambridge University Press; 2010:37-52.

5. Te Boveldt N, Vernooij-Dassen M, Burger N, Ijsseldijk M, Vissers $\mathrm{K}$, Engels Y. Pain and its interference with daily activities in medical oncology outpatients. Pain Physician. 2013;16(4):379-389.

6. Temel JS, JA Greer A, Muzikansky A, et al. Early palliative care for patients with metastatic non-small-cell lung cancer. $N$ Engl J Med. 2010;363(8):733-742.

7. Ripamonti CI, Santini D, Maranzano E, et al. Management of cancer pain: ESMO Clinical Practice Guidelines. Ann Oncol. 2012; 23(suppl 7):vii139-vii154.

8. World Health Organization [webpage on the Internet]. WHO's Cancer Pain Ladder for Adults. 2017. Available from: www.who.int/cancer/ palliative/painladder/en. Accessed June 13, 2017.

9. Caraceni A, Hanks G, Kaasa S, et al. Use of opioid analgesics in the treatment of cancer pain: evidence-based recommendations from the EAPC. Lancet Oncol. 2012;13(2):e58-e68.
10. World Health Organization. Cancer Pain Relief (Second Edition) with $a$ Guide to Opioid Availability. 1996. [cited Dec 22, 2016]; Available from: http://apps.who.int/iris/bitstream/10665/37896/1/9241544821. pdf. Accessed June 13, 2017.

11. Vithlani RH, Baranidharan G. Transdermal opioids for cancer pain management. Rev Pain. 2010;4(2):8.

12. Mercadante S. Pathophysiology and treatment of opioid-related myoclonus in cancer patients. Pain. 1998;74(1):5-9.

13. Bell T, Annunziata K, Leslie JB. Opioid-induced constipation negatively impacts pain management, productivity, and health-related quality of life: findings from the National Health and Wellness Survey. J Opioid Manag. 2009;5(3):137-144.

14. Holzer P, Ahmedzai SH, Niederle N, et al. Opioid-induced bowel dysfunction in cancer-related pain: causes, consequences, and a novel approach for its management. J Opioid Manag. 2009;5(3):145-151.

15. Estfan B, Mahmoud F, Shaheen P, et al. Respiratory function during parenteral opioid titration for cancer pain. Palliat Med. 2007;21(2):81-86.

16. Vissers KC, Besse K, Hans G, Devulder J, Morlion B. Opioid rotation in the management of chronic pain: where is the evidence? Pain Pract. 2010;10(2):85-93.

17. Reddy A, Yennurajalingam S, Desai H, et al. The opioid rotation ratio of hydrocodone to strong opioids in cancer patients. Oncologist. 2014;19(11):1186-1193.

18. Cachia E, Ahmedzai SH. Transdermal opioids for cancer pain. Curr Opin Support Palliat Care. 2011;5(1):15-19.

19. Gupta H, Babu R. Transdermal delivery: product and patent update. Recent Pat Drug Deliv Formul. 2013;7(3):184-205.

20. Pergolizzi J, Aloisi AM, Dahan A, et al. Current knowledge of buprenorphine and its unique pharmacological profile. Pain Pract. 2010;10(5):428-450.

21. Khanna IK, Pillarisetti S. Buprenorphine - an attractive opioid with underutilized potential in treatment of chronic pain. J Pain Res. 2015;8:859-870.

22. Trescot AM, Datta S, Lee M, Hansen H. Opioid pharmacology. Pain Physician. 2008;11(2 suppl):S133-S153.

23. Mercadante S, Vellucci R, Cuomo A, et al. Long-term efficacy and tolerability of intranasal fentanyl in the treatment of breakthrough cancer pain. Support Care Cancer. 2015;23(5):1349-1354.

24. Aurilio C, Pace M, Pota V, et al. Opioids switching with transdermal systems in chronic cancer pain. J Exp Clin Cancer Res. 2009;28(1):1.

25. Hanks GW, Conno F, Cherny N, et al. Morphine and alternative opioids in cancer pain: the EAPC recommendations. Br J Cancer. 2001;84(5):587-593.

26. UK NHS. Position Statement: Buprenorphine and Fentanyl Patches for Pain. 2015. Available from: http://www.lancsmmg.nhs.uk/download/ position $\% 20$ statements/Position \%20Statement.\%20Fentanyl\%20\&\%20 Buprenorphine\%20Patches\%20for\%20Pain\%20(Version\%201.0).pdf. Accessed June 13, 2017.

27. Skaer TL. Dosing considerations with transdermal formulations of fentanyl and buprenorphine for the treatment of cancer pain. J Pain Res. 2014;7:495.

28. Kang KH, Kuo LF, Cheng IC, Chang CS, Tsay WI. Trends in major opioid analgesic consumption in Taiwan, 2002-2014. J Formos Med Assoc. 2016. Epub 2016 Oct 4.

29. van Seventer R, Smit JM, Schipper RM, Wicks MA, Zuurmond WW. Comparison of TTS-fentanyl with sustained-release oral morphine in the treatment of patients not using opioids for mild-to-moderate pain. Curr Med Res Opin. 2003;19(6):457-469.

30. Hadley G, Derry S, Moore RA, Wiffen PJ. Transdermal fentanyl for cancer pain. Cochrane Database Syst Rev. 2013;(10):CD010270.

31. Melilli G, Samolsky Dekel BG, Frenquelli C, Mellone R, Pannuti F. Transdermal opioids for cancer pain control in patients with renal impairment. J Opioid Manag. 2014;10(2):85.

32. Mercadante S, Porzio G, Fulfaro F, et al. Switching from transdermal drugs: an observational "N of 1" study of fentanyl and buprenorphine. J Pain Symptom Manage. 2007;34(5):532-538. 
33. Sittl R, Likar R, Nautrup BP. Equipotent doses of transdermal fentanyl and transdermal buprenorphine in patients with cancer and noncancer pain: results of a retrospective cohort study. Clin Ther. 2005;27(2):225-237.

34. Sittl R, Nuijten M, Nautrup BP. Changes in the prescribed daily doses of transdermal fentanyl and transdermal buprenorphine during treatment of patients with cancer and noncancer pain in Germany: results of a retrospective cohort study. Clin Ther. 2005;27(7):1022-1031.

35. Sittl R, Nuijten M, Nautrup BP. Patterns of dosage changes with transdermal buprenorphine and transdermal fentanyl for the treatment of noncancer and cancer pain: a retrospective data analysis in Germany. Clin Ther. 2006;28(8):1144-1154.

36. Ahmedzai S, Brooks D; T-FCT Group. Transdermal fentanyl versus sustained-release oral morphine in cancer pain: preference, efficacy, and quality of life. J Pain Symptom Manage. 1997;13(5):254-261.

37. Apolone G, Mangano S, Compagnoni A, et al. A multidisciplinary project to improve the quality of cancer pain management in Italy: background, methods, and preliminary results. J Ambul Care Manage. 2006;29(4):332-341.

38. Kress HG, Von der Laage D, Hoerauf $\mathrm{KH}$, et al. A randomized, open, parallel group, multicenter trial to investigate analgesic efficacy and safety of a new transdermal fentanyl patch compared to standard opioid treatment in cancer pain. J Pain Symptom Manage. 2008;36(3): 268-279.

39. Mercadante S, Porzio G, Ferrera P, et al. Sustained-release oral morphine versus transdermal fentanyl and oral methadone in cancer pain management. Eur J Pain. 2008;12(8):1040-1046.

40. Wong J, Chiu G, Tsao C, Chang C. Comparison of oral controlledrelease morphine with transdermal fentanyl in terminal cancer pain. Acta Anaesthesiol Sin. 1997;35(1):25-32.

41. Payne R, Mathias SD, Pasta DJ, et al. Quality of life and cancer pain: satisfaction and side effects with transdermal fentanyl versus oral morphine. J Clin Oncol. 1998;16(4):1588-1593.

42. Corli O, Montanari M, Deandrea S, Greco MT, Villani W, Apolone G. An exploratory analysis on the effectiveness of four strong opioids in patients with cancer pain. Pain Med. 2012;13(7):897-907.
43. Mercadante S, Valle A, Porzio G, et al. Opioid switching in patients with advanced cancer followed at home. A retrospective analysis. J Pain Symptom Manage. 2013;45(2):298-304.

44. Tassinari D, Sartori S, Tamburini E, et al. Adverse effects of transdermal opiates treating moderate-severe cancer pain in comparison to long-acting morphine: a meta-analysis and systematic review of the literature. J Palliat Med. 2008;11(3):492-501.

45. Filitz J, Griessinger N, Sittl R, Likar R, Schüttler J, Koppert W. Effects of intermittent hemodialysis on buprenorphine and norbuprenorphine plasma concentrations in chronic pain patients treated with transdermal buprenorphine. Eur J Pain. 2006;10(8):743-748.

46. Mercadante S, Arcuri E. Opioids and renal function. J Pain. 2004;5(1):2-19.

47. Sittl R. Transdermal buprenorphine in cancer pain and palliative care. Palliat Med. 2006;20(8 suppl):25-30.

48. Plosker GL. Buprenorphine 5, 10 and $20 \mathrm{mug} / \mathrm{h}$ transdermal patch: a review of its use in the management of chronic non-malignant pain. Drugs. 2011;71(18):2491-2509.

49. Twycross RG, Wilcock A. Palliative Care Formulary. 4th ed. Palliativedrugs.com Ltd. Nottingham, UK. 2011.

50. Health Canada. Fentanyl transdermal patch and fatal adverse reactions. Can Adverse React Newsl. 2008;18(13):1-3.

51. FDA [webpage on the Internet]. FDA Reminds the Public About the Potential for Life-Threatening Harm from Accidental Exposure to Fentanyl Transdermal Systems ("Patches"). 2012.; Available from: http://www. fda.gov/Drugs/DrugSafety/ucm300747.htm. Accessed June 13, 2017.

52. Jumbelic MI. Deaths with transdermal fentanyl patches. Am J Forensic Med Pathol. 2010;31(1):18-21.

53. Walsh SL, Preston KL, Bigelow GE, Stitzer ML. Acute administration of buprenorphine in humans: partial agonist and blockade effects. J Pharmacol Exp Ther. 1995;274(1):361-372.

54. Dahan A, Yassen A, Romberg R, et al. Buprenorphine induces ceiling in respiratory depression but not in analgesia. Br J Anaesth. 2006;96(5):627-632.

55. Kress HG. Clinical update on the pharmacology, efficacy and safety of transdermal buprenorphine. Eur J Pain. 2009;13(3):219-230.
Journal of Pain Research

\section{Publish your work in this journal}

The Journal of Pain Research is an international, peer reviewed, open access, online journal that welcomes laboratory and clinical findings in the fields of pain research and the prevention and management of pain. Original research, reviews, symposium reports, hypothesis formation and commentaries are all considered for publication.

\section{Dovepress}

The manuscript management system is completely online and includes a very quick and fair peer-review system, which is all easy to use. Visit http://www.dovepress.com/testimonials.php to read real quotes from published authors. 